\title{
Research on the Institutional Leadership in the Transformation and Development of Private Colleges and Universities in Shaanxi Province and the Cultivation of Applied Talent
}

\author{
Sun Junhong \\ Xi'an International University, Xi'an, Shaanxi, 710077
}

Keywords: private colleges and universities; transformation and development; institutional leadership; cultivation of Applied Talent

\begin{abstract}
From the perspective of institutional designation of the government, from the central government to the provincial government, a series of policies has been carried out so as to lead the schools to transform into the applied schools; from the perspective of cultivating the talent, it is necessary to promote the construction of the vocational education, to strengthen the integration of teaching and the relevant industries, and to improve the cooperation between the schools and enterprises, so as to cultivate the high-quality workers and the applied talents. Combining and integrating the two perspectives above, the transformation of private colleges and universities in Shaanxi Province aims at vocational education, at the same time, the cultivation of applied talents also has been taken as the target and means of transformation. It is of great significance to break down the institutional obstacles and bottlenecks in the development and transformation of the private education, and to promote the healthy development of the private education.
\end{abstract}

In Shaanxi Province, there are 57 private colleges and universities (or institutes), including 9 private universities, 9 private vocational colleges, and 12 independent colleges; in these schools, 20 schools have the right to grant bachelor degrees, 1 school has the right to grant professional master degree $^{[1]}$. Private colleges and universities in Shaanxi Province have played an important role in increasing educational resources, providing educational choices and innovating the educational management system and mechanism. The purpose of the transformation and development of private colleges and universities in Shaanxi Province is to promote the transformation of more private colleges and universities in other provinces, or even to provide some useful references and experiences to other colleges and universities, "to realize the overall optimization of higher education structure in the foreseeable time, and to provide strong scientific, technological and talent supports for adapting and leading the New Normal situation of the economy in China, implementing innovation-driven strategy, and promoting the industrial transformation and upgrading" [2].

\section{Institutional Support for the Transformation and Development of Colleges and Universities}

On February 26th, 2014, the Executive Committee of the State Council held a meeting to clarify the policy that "to guide a number of universities that has the right to grant bachelor degree to transform into the applied and technology-oriented universities". In June 2014, the State Council issued the Decision on Speeding up the Development of Modern Vocational Education, in particular, "to guide a number of ordinary universities to transform into the applied technology universities, and the key point of this transformation is to run bachelor vocational education" ${ }^{33}$. At the some time, the State Council made the decision that "to develop the modern vocational education system that has Chinese characteristics and it will be top-class in the world".

Ministry of Education, National Development and Reform Commission, Ministry of Finance also issued the Guiding Opinions on Transforming Some Local Colleges and Universities into Applied Schools, it pointed out that "as the development of economy entering the New Normal, the relationship between supply and demand of talent has changed profoundly; facing the adjustment of 
the economic structure, the acceleration of industrial upgrading and transformation, and the constant improvement of construction of society and culture, especially the implementation of innovation-driving strategy, the structure contradiction of higher education becomes more and more serious. The education resources become similar, it is hard to find jobs or find good jobs for the graduates; at the some time, the schools also have not established the mechanism of cultivating the badly needed talents who have strong ability of innovation and who are the inter-disciplinary talents" ${ }^{[4]}$. It also pointed out 14 key tasks and put forward some countermeasures such as reforming comprehensively, overall planning by the provincial government, conducting tests at set up selected experimental points, making some models for providing experiences to the others, etc ${ }^{[2]}$.

The Notice on Publishing the Systematic Construction Planning of Shaanxi Modern Vocational Education (2015-2020) by the Education Department of Shaanxi Provencal Government and Other Five Departments pointed out that "to establish the modern vocational education system that is not only suitable for the development of the technology and the reform of ways of producing, but also suitable for the public services; in addition, the vocational education system not only has the Shaanxi characteristic, but also has the characteristics as below: the integration of industries and education must be improved deeply; secondary vocational education, higher vocational education, applied bachelor education, and professional master education should be closely tied and ensure the humorous development of them; vocational education and common education could promote the development each other, as well as the relationship between the vocational training and the human resource market, so as to actualize the systematization of the training of high-quality workers and skilled technical talents; to actualize the diversification of the learning forms and types of running schools; to build a scientific system that has a reasonable structure; at last, to promote Shaanxi to be a province which has strong educational strength and the centre of vocational education in West China” ${ }^{[5]}$.

The central government has made a fundamental arrangement, at the some time, the relevant functional departments and local government have all made arrangements for the development of private colleges and universities. So, the private colleges and universities in Shaanxi should improve and unify their understandings, "actively take measures to overcome all kinds of difficulties and find some breakthroughs, this is the right attitude and approach ${ }^{[6] "}$.

\section{Direction and Thinking of the Private Colleges and Universities for Transformation}

The Outline of the National Education Plan puts forward that----"to run a number of high level private schools". In June 2013, the Union of Applied Technology Universities was established in Tianjin University of Technology and Education. The first batch of 37 members had joined the union that contained 16 private colleges and universities. "This means that many local colleges and universities have been transforming into the applied technology universities, and this kind of transformation has been a kind of decision of the central government”. Moreover, we could judge from it that the private colleges and universities begin focusing on the vocational education and transforming into applied technology universities should also be the guiding direction for the central government to make decisions and the local government to govern private colleges and universities. Its general direction is that "it asks the higher education to transform the goal of education from cultivating the theoretical talents into cultivating the applied technology talents, the key factors are to make the position and methods of running private colleges and universities clear, to transform the teaching direction of colleges and universities into the cultivation of applied talents, to improve the students' ability of finding jobs, and to server the economic development of local area, so as to fit the current requirements of economic transformation and development of the local area” ${ }^{[7]}$.

In the fundamental planning of the central government, it emphasizes that the transformation of the private colleges and universities is a kind of reform that is systematic, comprehensive, and synergetic. At the macro level, it involves the relationship between the central government and the local government, the government and the schools, and the experimental schools and the non-experimental schools; at the medium level, it involves the relationship between the schools and 
the local government, local enterprises, local communities; at the micro level, it involves the internal structures of the schools, and the reform of cultivating the talents ${ }^{[2]}$.

The transformation into applied technology colleges and universities is the inevitable choice and important opportunity for private colleges and universities. In order to achieve this, the basic developmental thinking is that----the integration of the schools and the relevant industries, as well as the cooperation between the schools and relevant enterprises. At the some time, it is very important to pay attention to the team building of the teachers. Except the construction of the "double-position teachers", the private colleges and universities should take the advantage of the integration and cooperation between the enterprises and the schools; what's more, to pay more attention on innovation, and to adopt every feasible ways for management and innovation. To make the position of running schools clear for training applied talents, set up the proper majors to fulfill the needs of regional economic and social development, actively to promote the cooperative teaching model that is the combination of the schools and enterprises, and to strengthen the construction of experimental training bases in schools, and promote the applied scientific research becomes the link between teaching and serving the local area ${ }^{[8]}$.

\section{Cultivation of the Applied Talents is the Key Factor to the Transformation and Development of Private Colleges and Universities in Shaanxi Province}

It is necessary to solve the problems of development and strengthen the driving force of development and developmental advantages, we need to take the talents as the first resources and give full play to the role of the talents ${ }^{[9]}$. Talent is the first resource to support development. One of the main purposes of the country in building world-class universities and disciplines, developing vocational education in a large scale, and transforming itself into a university should "truly cultivate the talents who are very excellent, who can play a leading role in the development of the society, who can promote the progress of science, and who can adapt the furious global competition according to the actual requirement of the development in China ${ }^{10]}$.

Transformation and upgrading need talent support, the first issue in the process of transformation and upgrading of the private colleges and universities in Shaanxi Province is to decide what kind of talent the schools should cultivate? This is a question about position, and it also is a question that the schools must have a wonderful understanding about it. The "Supply-Side Structural Reform" in the field of national economy requires that the private universities in Shaanxi Province must cultivate "a large number of talents who have rich practical experiences in relevant industries and who are good at information industry. These talents must contain the public managerial talents who have the modern development sense and the ability of serving the market, have strong leadership and are good at innovation, understand the trend and innovative scientific research, and the technical talents who are very serious in modern manufacturing industry" ${ }^{[11]}$. Taking the students for example, the students of the top universities are not only the learners and receivers of the knowledge, but also the innovators and contributors. They should have noble moral qualities, generous knowledge reserve, and cute speculative ability, the ability of exploring initiatively, critical thinking and problem-solving ability ${ }^{[10]}$.

The local government should build the bridges between private colleges and universities in Shaanxi Province and the local enterprises or cultural industry organizations, and urge private colleges and universities to train practical talents with strong practical ability purposely for local development. It is necessary to gradually establish a mechanism for the talent cultivation which is led by the government, and in which the schools and enterprises participate; it is also necessary to have the institutional arrangement, and the participators jointly discuss the talent cultivation programs which are closely connect with majors of the schools and the posts of the enterprises; to draw up teaching plans according to needs, and to cultivate a number of applied talents who have the sense of social responsibility and professionalism, and who love their hometown. The local colleges and universities should insist on the position of cultivating the talents that "industry \& region”, and investigate the developmental situations of the economy, society, culture, and media, so as to make the reasonable short-term and long-term development planning of the regions; 
according the quantity vacancies of the posts in the next few years, to set up the majors and the planning of cultivating the talents, so as to serve the enterprises well and promote the development of the regions. What' more, it is necessary to do well in scientific research, to allow teachers to engage in pure theoretical academic research, and to encourage most of the teachers to across the boundary between academic research and applied research, and to focus on the issues that are more practical than academic. As long as the colleges, governments and enterprises work together, the talent cultivation of local colleges and universities will be full of vitality, and the quantity of the excellent applied graduates will increase quickly; this has been proved by the domestic and foreign practical activities to be an effective cooperative educational mechanism ${ }^{[12]}$. The principal part of the transformation is the local colleges and universities, and the local provincial governments are responsible for the transformation.

The integration of industry and education is the key factor of the structural reform on the supply-side of talents. Based on the great demand of the country, and the requirement of regional innovation and economic development, it is crucial to promote the deep integration of industry and education, and promote the systematic connection of education chain, talent chain, industry chain and innovation chain. At the some time, to provide constant supports of human resource for the economic development of the country and the region ${ }^{[13]}$.

To sum up, the comprehensive strength of private colleges and universities in Shaanxi takes the leading position in China, and the private higher education has become one of the achievements of Shaanxi after the policy of reform and opening up had been carried out. No matter from the aspect of system design at the national government, or from the aspect of governance of the local government, even from the aspect of practice of the private colleges and universities in Shaanxi, they all highlights the developmental direction of vocational education of the private colleges and universities in the process of transformation, as well as the cultivation of applied talents. By researching the issue of transformation of the private colleges and universities in Shaanxi Province, no matter the decision makers, practitioner, researchers, amateurs, or learners, they all could realize the current developmental situation of the private colleges and universities in Shaanxi Province. At the some time, the private colleges and universities also can realize that these private colleges and universities in Shaanxi Province have made great progress on increasing the resources of education, providing educational opportunities, innovating the managerial system and mechanism, so that these schools can accumulate more information for striving for the construction of "double first-class”, and form some characteristics of themselves in running schools.

\section{Acknowledgements}

Pro: Scientific Research Program Feunded by Shannxi Provincial Education Department (Program No. 15JZ054)

\section{References}

[1] 2016 Consultation Meeting on Admission of Private Colleges, Independent Colleges and Higher Vocational Colleges in Shaanxi Province Has Been Held [EB/OL]. http://news.cnr.cn/native/city/20160722/t20160722_522757843.shtml.

[2] Wang Feng, What Tendencies Should Be Avoided in the Transformation of Local Colleges and Universities[N] Guang Ming Daily, 2015-12-22(13).

[3] Que Mingkun. A Study on the Countermeasures of Constructing a High-level Private University of Applied Technology in China[D]. Northwest Normal University, 2015.

[4] Guiding Opinions of Ministry of Education, National Development and Reform Commission, Ministry of Finance on Transforming Some Local Colleges and Universities to Applied Schools, http://www.moe.edu.cn/srcsite/A03/moe_1892/moe_630/201511/t20151113_218942.html

[5] Notice on Publishing the Systematic Construction Planning of Shaanxi Modern Vocational 
Education (2015-2020) by the Education Department of Shaanxi Provencal Government and Other Five Departments[EB/OL].

http://wwww.snedu.gov.cn/news/jiaoyutingwenjian/201503/19/8964.html

[6] Lu Caichen. Local College Transforms to Applied Technology School: Difficulties and Breakthroughs[N]. Guang Ming Daily, 2014-11-11(14).

[7] Chen Shanman, Li Qiang, Wang Yuan. Discussion on the Basic Methods of Transformation and Development of Private Colleges and Universities in China[J]. Higher Education Exploration, 2016, (5).

[8] Xi'an International University Actively Explores and Innovates New Methods for Transforming to the Applied Technology [EB/OL]. http://www.snedu.gov.cn/jynews/rdjj/201409/18/43544.html.

[9] Luo Xu. To Provide Strong Human Resource Support for the Decisive Victory of Building a Well-off Society in an All-round Way[N]. Guang Ming Daily, 2016-02-03(03).

[10] Chen Jun. On Cultivating the Excellent talents to Support the Innovative Development[N]. Guang Ming Daily, 2016-03-08(06).

[11] Yue Wenhou. Transformation and Upgrading Require the Support of the Talents[N]. Guang Ming Daily, 2016-05-31(16).

[12] Gao Youxiang. Local Colleges and Universities Should have the Unique Characteristics and Mission[N]. Guang Ming Daily,2015-12-22(13).

[13] Wang Qinghuan. Marching Towards to the Deep Integration of production and teaching[N]. Guang Ming Daily, 2017-12-20(12).

\section{About the Author:}

Sun Hongjun (1974-), Comes form Ruzhou, Henan Province.

Titles: Editor of Qifang Education Research Institute, Xi'an International University; Philosophy Doctor.

Research Direction: Private Higher Education; Educational Philosophy. 